\title{
Anodic Stripping Voltammetry of Uric Acid at Glassy Carbon Electrodes after Pre-Electrolysis in Solution Containing Copper(II)
}

\author{
Haruki ShIRAISHI and Reiji TAKAHAShI \\ Department of Chemistry, Ritsumeikan University, Tohjiin Kitamachi, Kyoto 603-77, Japan
}

Keywords Anodic stripping voltammetry, uric acid, glassy carbon electrode, copper(I)-uric acid complex

The electrochemistry of biologically important compounds has recently been extensively studied. Uric acid is one of the purine derivatives whose oxidation mechanisms have attracted much attention with respect to metabolism in vivo as well as analytical applications. Dryhurst and co-workers have reported on the electrochemical oxidation of uric acid at carbon electrodes. ${ }^{1,2}$ Yao and co-workers have applied anodic voltammetry to the determination of uric acid and other purine derivatives. ${ }^{3}$

In previous studies, we found that the oxidation currents of uric acid and other purine bases at glassy carbon electrodes (GCE) were extremely enhanced by pre-electrolysis with $\mathrm{Cu}^{\mathrm{II}}$ in solution. ${ }^{4}$ In the case of adenine or guanine, a complex between the base and $\mathrm{Cu}^{\mathrm{l}}$, electrogenerated in pre-electrolysis and deposited on GCE, was responsible for the current amplification. ${ }^{5}$ The interaction between uric acid and $\mathrm{Cu}^{\mathrm{I}}$ was studied in the present work.

\section{Experimental}

\section{Chemicals}

Uric acid was purchased from Merck \& Co., Inc. and used without further purification. $\mathrm{A} \mathrm{Cu}$ II solution was prepared from copper acetate of analytical grade. Every sample solution was prepared from an analyticalgrade reagent in doubly distilled water.

\section{Apparatus}

A three-electrode voltammetric cell maintained at $25^{\circ} \mathrm{C}$ was used throughout. A saturated calomel electrode (SCE) was employed as a reference electrode, and a platinum wire as a counter electrode. GCE was made from a 3-mm $\phi$ rod of glassy carbon (GC30s, Tokai Carbon Co.); its working surface was polished to a mirror finish.

Anodic stripping voltammograms were recorded with a Fuso potentiostat (Model 311) and a Graphtec $x-y$ recorder. UV spectra were measured on a Shimadzu spectrophotometer (Model UV-240).

\section{Procedure}

The anodic stripping of uric acid was carried out as in previous studies.4,5 Briefly, a uric acid solution containing $\mathrm{Cu}^{\mathrm{II}}$ and the background electrolyte was preelectrolyzed at an initial potential $\left(E_{i}\right)$ on a GCE rotated so as to stir the test solution. After pre-electrolysis the potential of GCE was scanned to positive values so as to obtain the anodic peaks of uric acid.

\section{Results and Discussion}

Large oxidation currents were observed on the anodic stripping voltammograms, recorded as mentioned above (Fig. la, b). Two oxidation peaks appear in the voltammogram: a sharp peak $\left(i_{\mathrm{p} 1}\right)$ at $0.5 \mathrm{~V}$ and a broad

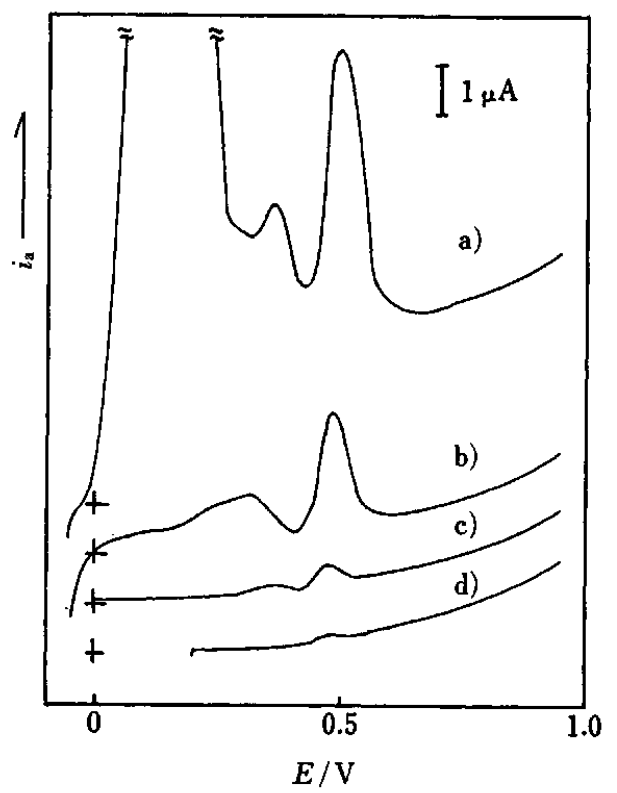

Fig. 1 Influence of the pre-electrolysis potential $\left(E_{\mathrm{i}}\right)$ on the anodic voltammogram of uric acid at GCE. Test solution: $4 \times 10^{-6} \mathrm{M}$ uric acid, $0.4 \times 10^{-3} \mathrm{M} \mathrm{Cu}^{\mathrm{II}} \cdot E_{\mathrm{i}}(\mathrm{V})$ : a) -0.10 ; b) -0.05 ; c) 0 ; d) 0.20 . Pre-electrolysis period: $180 \mathrm{~s}$. 


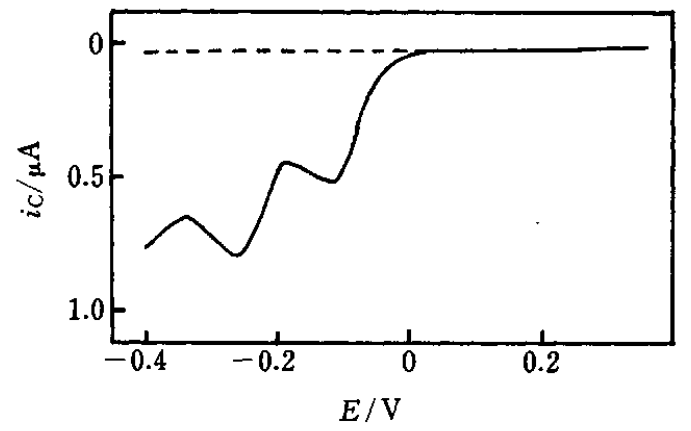

Fig. 2 Cathodic voltammogram of $2 \times 10^{-4} \mathrm{M}$ copper(II) at GCE. Scan rate, $50 \mathrm{mV} / \mathrm{s}$; broken line, background current.

peak $\left(i_{\mathrm{p} 2}\right)$ at around $0.35 \mathrm{~V}$. The former peak may reflect the oxidation of uric acid since it depends on the uric acid concentration; the latter peak is absent in electrolytes not containing $\mathrm{Cu}^{\mathrm{II}}$.

\section{Conditions for the anodic stripping process}

The oxidation peaks of uric acid were influenced by the solution $\mathrm{pH}$, the concentration of $\mathrm{Cu}^{\mathrm{II}}$, the initial potential $\left(E_{\mathrm{i}}\right)$ and the pre-electrolysis period $\left(\tau_{\mathrm{d}}\right)$. Based on the knowledge acquired in a previous study ${ }^{4}, \mathrm{a} \mathrm{pH}$ value of 3.8 (Britton-Robinson buffer) and a $\mathrm{Cu}^{\text {II }}$ concentration of $0.4 \mathrm{mM}$ were employed. The effect of $E_{\mathrm{i}}$ on the oxidation current can be seen in Fig. 1. The current $\left(i_{\mathrm{p} 1}\right)$ reached a maximum when $E_{\mathrm{i}}$ was $-0.1 \mathrm{~V}$, while no anodic stripping peaks were obtained for $E_{\mathrm{i}} \geqq 0.2 \mathrm{~V}$ and $E_{\mathrm{j}} \leqq-0.2 \mathrm{~V}$. The magnitude of $i_{\mathrm{p} 1}$ for $E_{\mathrm{i}}=0.2 \mathrm{~V}$ was the same in both the presence and absence of $\mathrm{Cu}^{\mathrm{II}}$ in the solution. The anodic stripping process is presumably prevented by metallic copper on GCE. For $E_{\mathrm{i}}=-0.1 \mathrm{~V}$, a large reoxidation peak of metallic copper is seen on the stripping voltammogram; this renders any estimation of the residual current quite difficult. Hence, an appropriate $E_{\mathrm{i}}$ may be $-0.05 \mathrm{~V}$, rather than $-0.1 \mathrm{~V}$, for obtaining the anodic stripping peak of uric acid for analytical purposes.

When $E_{\mathrm{i}}$ was set at a potential at which $\mathrm{Cu}^{\mathrm{II}}$ was reduced to metallic copper or not reduced at all, the oxidation current of uric acid was not enhanced. These results indicate that the anodic stripping process is related to the reduction of $\mathrm{Cu}^{\mathrm{II}}$.

\section{Reduction of copper(II) during pre-electrolysis}

$\mathrm{Cu}^{\mathrm{II}}$ gave two reduction peaks at GCE (Fig. 2). A cyclic voltammetric study showed that the more positive peak $\left(E_{\mathrm{p}}=-0.12 \mathrm{~V}\right)$ reflects the reduction of $\mathrm{Cu}^{\text {II }}$ to $\mathrm{Cu}^{\mathrm{I}}$ and the other $\left(E_{\mathrm{p}}=-0.26 \mathrm{~V}\right)$ the reduction to metallic copper. ${ }^{6} \mathrm{Cu}^{1}$ electrogenerated at $\mathrm{GCE}$ is reoxidized reversibly to $\mathrm{Cu}^{\mathrm{II}}$, while metallic copper is reoxidized directly to $\mathrm{Cu}^{\mathrm{II}}$. In the course of pre-electrolysis, $\mathrm{Cu}^{\mathrm{II}}$ may be partially reduced to $\mathrm{Cu}^{\mathrm{i}}$.

\section{Reaction between uric acid and copper( $(I)$}

It is known that uric acid reacts with $\mathrm{Cu}^{\mathrm{l}}$, generated by

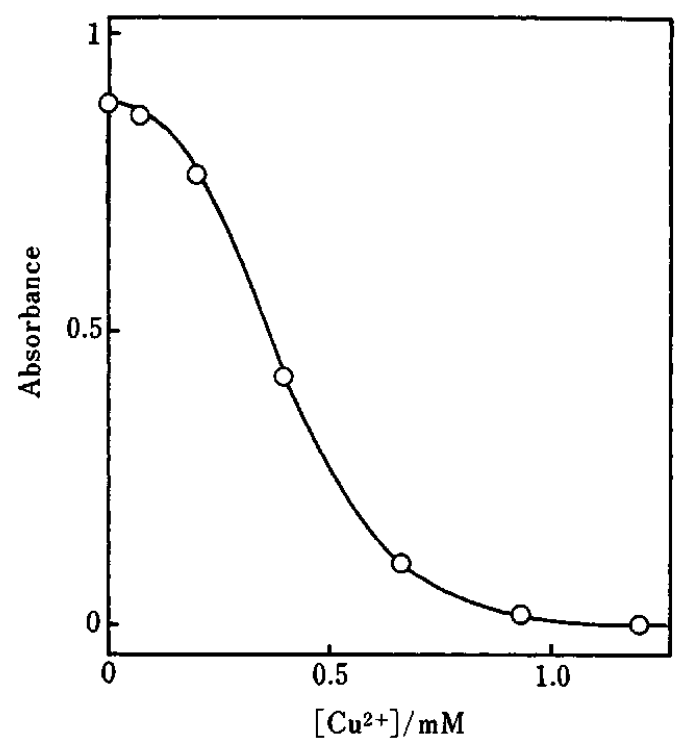

Fig. 3 Decrease in the uric acid concentration due to its reaction with $\mathrm{Cu}^{\mathrm{I}}$. Abscissa: concentration of $\mathrm{Cu}^{\mathrm{II}}$ added to a mixture of $8 \times 10^{-5} \mathrm{M}$ uric acid and $2 \times 10^{-3} \mathrm{M}$ hydroxylamine. Ordinate: absorbance of uric acid in the supernatant. See text for details.

the addition of hydroxylamine to a $\mathrm{Cu}^{11}$ solution ${ }^{7}$, giving a white precipitate. This precipitate may be a $\mathrm{Cu}^{\mathrm{I}}$ compound, since it is oxidized by passing atmospheric oxygen and is redissolved in solution. UV spectrophotometry of the supernatant solution, obtained by the addition of hydroxylamine to a $\mathrm{Cu}^{\mathrm{II}}$ solution containing uric acid, confirmed the reaction between $\mathrm{Cu}^{\mathrm{I}}$ and uric acid. The absorbance of uric acid in the supernatant at $283 \mathrm{~nm}$ was decreased by increasing the amount of generated $\mathrm{Cu}^{\mathrm{I}}$ (Fig. 3). When the concentration of hydroxylamine was higher than $1 \mathrm{mM}$, the absorbance of uric acid reached zero and uric acid was completely precipitated. Since the absorbances of $\mathrm{Cu}^{\mathrm{II}}, \mathrm{Cu}^{1}$ and hydroxylamine were sufficiently small at $283 \mathrm{~nm}$, a mixed solution of $\mathrm{Cu}^{\mathrm{II}}$ and hydroxylamine was used as a reference. Presumably, excess $\mathrm{Cu}^{\mathrm{I}}$ caused the uric acid to precipitate quantitatively as the $\mathrm{Cu}^{1}$ complex.

\section{Mechanism of the current enhancement}

Based on these pieces of evidence, the anodic stripping of uric acid at GCE may proceed as follows:

1. During pre-electrolysis at $E_{\mathrm{i}}$, where $\mathrm{Cu}^{\mathrm{II}}$ is reduced to $\mathrm{Cu}^{\mathrm{I}}$, uric acid is accumulated on the surface of GCE as the precipitate of a $\mathrm{Cu}^{1}$ compound.

2. When the electrode potential reaches $c a .0 .3 \mathrm{~V}$ on the anodic scan, $\mathrm{Cu}^{1}$ of the compound is reoxidized to $\mathrm{Cu}^{\mathrm{II}}$ and the precipitate is redissolved. The uric acid concentration in the vicinity of GCE is considerably increased by this process, yielding a large oxidation peak at $0.5 \mathrm{~V}$.

This stripping method facilitates the determination of a micromolar concentration of uric acid. Other purine derivatives may also be determined in a similar manner. 


\section{References}

1. R. N. Goyal, A. Brajter-Toth and G. Dryhurst, J. Electroanal. Chem. Interfacial Electrochem., 131, 181 (1982).

2. G. Dryhurst, N. T. Nguyen, M. Z. Wrona, R. N. Goyal, A. Brajter-Toth, J. L. Owens and H. A. Marsh, Jr., J. Chem. Education, 60, 315 (1983).

3. T. Yao, Y. Ueda, T. Wasa and S. Musha, Bull. Chem. Soc. Jpn., 51, 2937 (1978).
4. H. Shiraishi and R. Takahashi, Bunseki Kagaku, 37, 41 (1988).

5. H. Shiraishi and R. Takahashi, Bunseki Kagaku, 34, 1 (1985).

6. H. Shiraishi and R. Takahashi, Bioelectrochem. Bioenerg., 31, 203 (1993).

7. H. Anderson, Analyst [London], 91, 523 (1966).

(Received August 23, 1993) (Accepted November 26, 1993) 